Musa et al., Afr. J. Infect. Dis. 2(1): 00 - 00

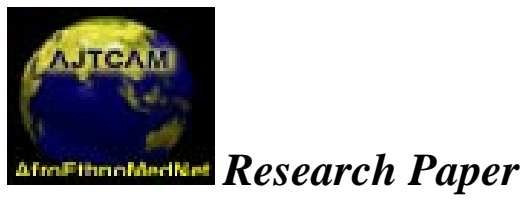

Afr. J. Infect. Diseases

www.africanethnomedicines.net

ISSN: 2006-0165@2008

\title{
FAMILY COMMUNICATION ON HIV / AIDS AMONG SECONDARY SCHOOL STUDENTS IN A NORTHERN STATE OF NIGERIA
}

\author{
*O. I. Musa , *T. M. Akande, *Salaudeen A. G. ～+O. M. Soladoye \\ *Dept of Epidemiology \& Community Health, College of Medicine, University of Ilorin, Ilorin, \\ Nigeria. +Dept of General Medical Practice University of Ilorin Teaching Hospital, Ilorin, Nigeria. \\ +E-mail: mtosh2002@yahoo.com
}

\begin{abstract}
Most Adolescents in Nigeria, like many others in Africa, are potentially at risk for contracting HIV through unprotected sexual intercourse. Yet the issue of how to help youth avoid risky sexual behaviour through family communication / education on HIV/AIDS is still of serious arguments within the society. This study examines the practice of family communication on HIV / AIDS among secondary school students. A descriptive study using 420 secondary school students selected by multi-stage random sampling was done. Self administered semi-structured questionnaire was used to collect relevant data. Only 48 (12.1\%) reported family as the first source of information. However, most of the students $315(79.7 \%)$ had family communication on HIV/AIDS with their family members. There is a gender difference in practice of family communication. Significantly higher proportion of the female students had family communication more than their male counterparts. The educational status of the parents significantly determined whether or not a student had family communication on HIV/AIDS. There is considerable level of family communication in the study population which should be encouraged further to cut across all members of the family.
\end{abstract}

Key words: Family communication, HIV/AIDS, Students, HIV and Communication

\section{Introduction}

Everyday, about 15,000 people throughout the world become infected with HIV. Sixty percent of these people are women and men aged 15 to 24 years; and countries of Sub-Saharan Africa are the most acutely affected by the HIV epidemic (UNAIDS, 1999). According to the Joint United Nations Programme on HIV/AIDS (UNAIDS, 1999); two-thirds of the global total of 40 million people estimated to be HIV-positive lives in this region. Most Adolescents in Nigeria, like many others in Africa, are potentially at risk for contracting HIV through unprotected sexual intercourse. Yet the issue of how to help youth avoid risky sexual behaviour through family communication/education on HIV/AIDS is still of serious arguments within the society.

Most adolescents in Nigeria become sexually active before marriage, many while still in their teens. Studies (Unuigbe et al. 1999; Fawole et al. 1999) have shown that up to 50\% of unmarried young people aged 15 - 19years had begun sexual activity. The mean age of sexual initiation was 14.8 years. Most teenagers engaged in sex without proper protection. Family communication between teenagers and their parent about sexuality and HIV/AIDS can influence this high risk behaviour and practices. This study was conducted to determine the practice of family communication on HIV/AIDS among high school students with a view to identifying important factors that determine the practice of family communication on HIV/AIDS between parents and their children or wards.

\section{Methodology}

This descriptive study was carried out among high school pupils in Ilorin, one of the major cities in the North Central region of Nigeria. Ilorin comprises of 18 administrative wards and has 48 high schools (secondary 
schools). Thirty-three of the schools were public schools and 15 were private. Out of the 48 schools, 13 were "uni-sex" (all students are of the same sex) while 35 had both sexes as students.

Sample size for the study was calculated using Fisher's formula, and a minimum sample size of 310 was arrived at. However, 420 students were approached and involved in the study. Multi-stage sampling technique was used to randomly select wards and schools within Ilorin that were used for the study. The number of students sampled from each school was proportionately determined based on the student population. Final selection of the students interviewed was done through systematic random sampling technique using the students' register as the sampling frame. Students in the second year of the senior secondary schools (SS 2) were used because of their relatively matured age; and also for the fact that students in third year of the senior secondary schools (SS 3) were taking their final Senior Secondary Certificate Examination (SSCE), hence were not readily available.

Informed consent was obtained from each student before being issued a questionnaire. The semi-structure questionnaire was distributed to the participants for self administration. Information on the bio-data of the respondents and questions relating to family communication on HIV/AIDs were major issues captured in the questionnaire. All completed questionnaires were returned to the research Assistants on the same day. Manual checking of the returned questionnaires was done and 395 were found to be properly completed and suitable for analysis. This gave a response rate of $94 \%$. Data entry and analysis was done on micro-computer using EPI2000 software. Chi-square test was used to determine the statistical difference in cross tabulated variables with level of significant set at $\mathrm{P}$ value $<0.05$.

Table 1: Age - Sex Distribution of the respondents and First source of Information on HIV / AIDS

\begin{tabular}{|lccc|}
\hline Age group (years) & Male & Female & Total \\
\hline$\leq 15$ yrs. & $31(7.8 \%)$ & $22(5.6 \%)$ & $53(13.4 \%)$ \\
& & & \\
$16-20$ & $167(42.3 \%)$ & $137(34.7 \%)$ & $304(77.0 \%)$ \\
& & & \\
Total & $\mathbf{2 3 3}(\mathbf{5 8 . 8 \% )}$ & $\mathbf{1 6 2}(\mathbf{4 1 . 2 \% )}$ & $\mathbf{3 9 5}(\mathbf{1 0 0} \%)$ \\
& & & \\
& & & \\
& & & \\
First Information source & Frequency & Percentage (\%) \\
& & 22 \\
Electronic Media & 88 & 19 \\
Print media & 76 & 28 \\
Peers / friends & 111 & 6 \\
Teachers & 22 & 12 \\
Family member & 48 & 13 \\
Health workers & 50 & $100 \%$ \\
Total & 395 & \\
\hline
\end{tabular}

\section{Results}

Majority of the respondents were male 233 (58.9\%); and over three-quarters of the students were within the age group 16-20 years, with a mean age of $16.7 \pm 2.3$ years (Table 1). About two-thirds $250(63.3 \%)$ of the students were from monogamous family; while the rest were from polygamous homes. Respondents with family size of 6 or more persons 371(93.9\%) were more than those with family size of less than six 24(6.1\%). All the students had some information about HIV/AIDs, and the commonest source of first information on HIV/AIDs was the electronic media 111(28.1\%). Only 48(12.1\%) reported family as the first source of information (Table 1).

However, most of the students claimed to have had family communication on HIV/AIDs with their family members 315 (79.7\%). Some of the issues discussed on HIV/AIDs by the family included: HIV transmission 315(100\%), use of condom 309(98\%) and pre-marital sex 106(33.7\%) (Table 2). The member of the family often involved in family communication was the mother 137 (43.5\%), followed by the father 91 $(28.9 \%)$. There is a gender difference in practice of family communication. Higher proportion of the female students had family communication more than their male counterparts. This is statistically significant $\mathrm{P}=0.0249$. Similarly students with family size of 5 or less tend to have family communication more than those with larger family size. This is also statistically significant $\mathrm{P}=0.0223$ (Table 3). Also, the educational status of the parents 
significantly determined whether or not a student had family communication on HIV/AIDS $(\mathrm{P}=0.00001)$. However, there was no significant difference in proportion of students with family communication among polygamous and monogamous family.

Table 2: Family communication on HIV/AIDS

\begin{tabular}{|rr}
\hline $\begin{array}{l}\text { a. Aspects of HIV/AIDS discussed } \\
\text { Issues on HIV/AIDS discussed }\end{array}$ & \\
\hline & Frequency (\%) \\
Mode of transmission of HIV & $315(100 \%)$ \\
Use of condom & $309(98 \%)$ \\
Multiple sexual partner & $56(17.8 \%)$ \\
Sexual behaviour / practices & $50(15.9 \%)$ \\
Premarital sex & $106(33.7 \%)$ \\
\hline b. Family members most involved in communication on HIV/AIDS & \\
Family Member & Frequency (\%) \\
Mother & $137(43.5 \%)$ \\
Father & $91(28.9 \%)$ \\
Sister & $34(10.8 \%)$ \\
Brother & $53(16.8 \%)$ \\
Total & $\mathbf{3 1 5 ( 1 0 0 \% )}$ \\
\hline
\end{tabular}

Table 3: Factors influencing the practice of family communication

\begin{tabular}{|c|c|c|c|c|}
\hline \multirow[b]{2}{*}{ Factors } & \multicolumn{3}{|c|}{ Practice of family communication } & \multirow[b]{2}{*}{ P-value } \\
\hline & Yes & No & Total & \\
\hline \multicolumn{5}{|l|}{$\overline{\text { Sex }}$} \\
\hline Male & $177(76 \%)$ & $56(24 \%)$ & 233 & \\
\hline Female & $138(86 \%)$ & $24(15 \%)$ & 162 & 0.0249 \\
\hline \multicolumn{5}{|l|}{ Family size } \\
\hline$\leq 5$ & $24(100 \%)$ & $0(0 \%)$ & 24 & \\
\hline$\geq 6$ & $291(79.8 \%)$ & $80(20.2 \%)$ & 371 & 0.0223 \\
\hline \multicolumn{5}{|l|}{ Family Type } \\
\hline Polygamy & $116(80.0 \%)$ & $29(20.0 \%)$ & 145 & \\
\hline Monogamy & $199(79.6 \%)$ & $51(20.4 \%)$ & 250 & 0.9240 \\
\hline \multicolumn{5}{|c|}{ Father's Educational Status } \\
\hline Formal Education & $295(85.5 \%)$ & $50(14.5 \%)$ & 345 & \\
\hline No formal education & $20(40.0 \%)$ & $30(60.0 \%)$ & 50 & 0.00001 \\
\hline \multicolumn{5}{|c|}{ Mother's Educational Status } \\
\hline Formal Education & $258(86.0 \%)$ & $42(14.0 \%)$ & 300 & \\
\hline No formal education & $57(60.0 \%)$ & $38(40.0 \%)$ & 95 & 0.00001 \\
\hline
\end{tabular}

\section{Discussion}

HIV/AIDS pandemic is a major health problem in developing countries. The most affected age-group are young people aged 15-24. Students in this study population are aged between $16-20$ years and are within the sexually active population that is at risk of HIV/AIDS as reported by Adu-Mireku 2003. The major source of information on HIV/AIDS transmission among these students is electronic media. In developing countries the electronic media is among the leading source of health information among educated people. This source of information unfortunately is also the common source of information that promotes sexual activity among the young adults. In this study, the family is not the major source of information and is a reflection of the low level of communication between parents and children in developing countries on issues related to sex. Study by Miller et al. (1998), showed that discussions about HIV with parents tend to decrease the likelihood that adolescents will engage in risky behavior, while communication with peers tends to increase that likelihood. 


\section{Musa et al., Afr. J. Infect. Dis. 2(1): 00 - 00}

The family is a primary agent of socialization and can exert a strong influence on adolescent sexual behaviour but in a situation where most secondary school students as in this study get more information from the electronic media, the family, therefore, may be exerting little or no influence on their sexual behaviour as earlier reported by Steinberg 2001. Studies by Airhihenbuwa et al. (2004) and Yahaya (20002) revealed that culture of the people in this part of the world do not really promote discussion on sex between parents and their children. Culture is known to play a vital role in determining the health of the individual and the family. Positive communication between parents and children helps young people to establish individual values and make sexually healthy decisions. Although most adults want youth to know about abstinence, contraception, and how to prevent HIV and other sexually transmitted infections (STIs), parents often have difficulty communicating about sex.

However, in this study about $80 \%$ of the students had family communication about sex, this is similar to finding of a similar study conducted among senior secondary school students in Ghana (Adu-Mireku, 2003) and comparable with findings from a survey conducted by O'Sullivian et al. (2001) among African Americans and Latinos. This finding is encouraging that many more parents in parts of Africa are getting beyond culture to communicate with their children to promote their sexual health. The increasing prevalence of HIV/AIDS and the fear of the nature of the disease might have contributed immensely to this positive change on family communication in Africa.

The commonly discussed issues during family communication on HIV/AIDS as shown in this study include transmission of HIV/AIDS, use of condom while a few discuss pre-marital sex. It appears from this finding that most parents are almost giving up on avoidance of pre-marital sex among their children as adolescent sexuality is on the increase but they focus discussion mainly on measures like use of condom to prevent HIV/AIDS. A study of urban African American and Latino mothers and their pre-teen and early adolescent daughters found many mothers reluctant to discuss more than biological issues and negative consequences of sexual activity. Maternal communications about sex that is often restrictive and moralistic in tone, deterred daughters from confiding in their mothers. Daughters, in reaction, sometimes became secretly involved in romantic relationships (O’Sullivian et al. 2001; Holtzman et al., 1995).

This study revealed that more mothers than fathers discuss on HIV/AIDS with their children. In this part of the world women find more time to communicate with their children than men. Also more females than male students have family communication on HIV/AIDS. Previous studies (by Di Lorio et al., 1999; Raffaelli et al., 1998; Lefkowitz et al., 2002) reported similar finding. The students with smaller size families and those whose parents are educated communicate significantly more on HIV/AIDS than those with larger family size and the uneducated. The educated parents are the ones that are likely to have smaller family size and are the groups of parents who are also less likely to be bound to cultural beliefs and practices that limit communication between parents and their children.

The apparent improvement in communication between parents and their teens on issues like sexuality in developing countries is encouraging. The concern of parents on their children not been infected with the dreaded disease probably influenced this. This development need to be widespread to include every family irrespective of social status and culture to help stem the increasing prevalence of HIV/AIDS particularly among adolescents.

\section{References}

1. Adu-Mireku, S. (2003). Family communication about HIV/AIDS and sexual behaviour among senior secondary school students in Accra, Ghana. Afr. Hlth. Sc., 3(1): 7-14.

2. Airhihenbuwa C.O. and Webster J.D. (2004). Culture and African contexts of HIV/AIDS prevention, care and support. SAHARA Journal 1(1): 4-13.

3. DiLorio, C., Kelley, M., and Hockeberry-Eaton, M. (1999). Communication about sexual issues: mothers, fathers and friends. J. Adolescents Hlth., 24: 181-9.

4. Fawole, I O, Asuzu, M C, Oduntan, S. O, and Brieger, W. R. (1999). A school based AIDS education programme for secondary schools in Nigeria. Hlth Education Res., 14(5): 675 - 83.

5. Holtzman, D. and Rubinson, R. (1995). Parent and peer communication effects on AIDS-related behavior among U. S. high school students. Family Planning Perspective, 27:235-40.

6. Lefkowitz, E. S., Boone, T. L., Sigman, M., and Kit-fong, A.T. (2002). He said, she said: Gender differences in mother-adolescent conversations about sexuality. J.Res. Adolescence, 12: 217-242

7. Miller, K.S., Kotchick, B. A., Dorsey, S., Forehand, R. and Ham, A.V. (1998). Family Communication About Sex: What Are Parents Saying and Are Their Adolescents Listening? Family Planning Perspectives, 30(5):218-222. 
Musa et al., Afr. J. Infect. Dis. 2(1): 00 - 00

8. O'Sullivan, L. F, Mayer-Bahlburg, H.F.L, and Watkins, B. X. (2001). Mother-daughter communication about sex among urban African American and Latino families. J. Adolescents Res.,16: 269-92.

9. Raffaelli, M., Bogenschneider, K., and Flood, M. F. (1998). Parent-teen communication about sexual topics. J. Family Issues, 19: 315-333.

10. Steinberg L. (2001). We know some things: parent-adolescent relationships in retrospect and prospect. J. Res.n Adolescents, 1(11):1-19.

11. UNAIDS (1999). (Document UNAIDS /01.02E). The world AIDS campaign; 7-9

12. Unuigbe, I E., and Osafu, O. (1999). Sexual behaviour and perception of AIDS among adolescent Girls in Benin City, Nigeria. Afr.J. Reproductive Hlth., 3(1): 39 - 44.

13. Yahaya, M. K. (2002). Analysis of Women's Reproductive Health Situation in Bida Emirate of Niger State, Nigeria. Afr. J. Reproductive Hlth., 6(1): 50-64 